\section{Brain Injury Awareness Month - March 2020}

Brain Injury Awareness Month, recognized each March, provides an important opportunity to bring attention to the prevention of traumatic brain injury (TBI) and to promote strategies to improve the quality of life for persons living with TBI and their families.

TBIs, caused by an impact or force to the head or body or a penetrating injury to the head, affect millions of U.S. persons each year (1). Falls are a leading mechanism of TBI, and older adults are at increased risk for sustaining a TBI and experiencing TBI-associated adverse outcomes $(1,2)$. A report in this issue of $M M W R$ found a nationwide $17 \%$ increase in the rate of fall-related TBI deaths during 2008-2017, with increases in most states (3). The largest increases in fall-related TBI deaths occurred among persons aged $\geq 75$ years.

Evidence-based prevention efforts to decrease falls are important to reducing the incidence and prevalence of TBI among older adults. CDC's STEADI (Stopping Elderly Accidents, Deaths \& Injuries; https://www.cdc. gov/steadi/index.html) initiative includes resources and tools for health care providers to improve identification of patients at risk for a fall, as well as effective strategies to reduce the risk for fall-related injuries, including TBI.

\section{References}

1. CDC. Surveillance report of traumatic brain injury-related emergency department visits, hospitalizations, and deathsUnited States, 2014. Atlanta, GA: U.S. Department of Health and Human Services, CDC; 2019.

2. Taylor CA, Bell JM, Breiding MJ, Xu L. Traumatic brain injuryrelated emergency department visits, hospitalizations, and deaths_-United States, 2007 and 2013. MMWR Surveill Summ 2017;66(No. SS-9). https://doi.org/10.15585/mmwr.ss6609a1

3. Peterson AB, Kegler SR. Deaths from fall-related traumatic brain injury-United States, 2008-2017. MMWR Morb Mortal Wkly Rep 2020;69:225-30.

\section{Deaths from Fall-Related Traumatic Brain Injury - United States, 2008-2017}

\author{
Alexis B. Peterson, $\mathrm{PhD}^{1}$; Scott R. Kegler, $\mathrm{PhD}^{1}$
}

One in 10 U.S. residents aged $\geq 18$ years reports falling each year (1). Among all age groups, falls can cause serious injury and are the second leading cause of traumatic brain injury (TBI)-related deaths (2). TBI is a head injury caused by a bump, blow, or jolt to the head or body or a penetrating head injury that results in disruption of normal brain function.* CDC estimated national and state-specific rates and trends for TBI-related deaths (TBI deaths) caused by unintentional falls (fall-related TBI deaths) among U.S. residents during 2008-2017, by selected decedent characteristics. The national age-adjusted rate of fall-related TBI deaths increased by $17 \%$

$\overline{{ }^{*} \text { https://www.cdc.gov/traumaticbraininjury/index.html. }}$

\section{INSIDE}

231 Student-Reported School Safety Perceptions, Connectedness, and Absenteeism Following a Multiple-Fatality School Shooting - Broward County, Florida, February 14-21, 2018

236 E-cigarette, or Vaping, Product Use-Associated Lung Injury Among Clusters of Patients Reporting Shared Product Use - Wisconsin, 2019

241 Intervention To Stop Transmission of Imported Pneumonic Plague — Uganda, 2019

245 Active Monitoring of Persons Exposed to Patients with Confirmed COVID-19 — United States, January-February 2020

247 Notes from the Field: Monkey Bite in a Public Park and Possible Exposure to Herpes B Virus — Thailand, 2018

249 QuickStats

Continuing Education examination available at https://www.cdc.gov/mmwr/mmwr_continuingEducation.html

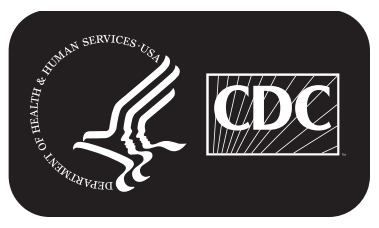

U.S. Department of Health and Human Services Centers for Disease Control and Prevention 